\title{
Changing Travel Patterns of Older Women Policy, Safety and Mobility
}

\author{
A TALK by SAndRa Rosenbloom
}

Geiska Baker is the author of this edited transcription of Dr. Sandra Rosenbloom's presentation at the CRP Department on May 11, 2006. Dr. Rosenbloom thesis is that transportation planning must meet different needs from different users, and be able to respond to market segmentation. She discussed the importance of identifying the travel patterns of older women in planning for an aging population and presented research information from the US and Great Britain

There is a potpourri of transportation issues facing older-people; but more particularly older women because they face different problems and have different resources than older men. In general, there are very few older women in comparable positions to older men. Older men are more advantaged in a number of ways and this is revealed in their travel patterns, mobility patterns and general life style.

\section{Differing travel patterns}

Older women are substantially less likely to have a driver's license in the US and abroad. At all ages, women travel fewer miles by any mode than comparable men. Compared to the behavior of younger women, older women make fewer daily trips than older men and more often use alternatives to the car. As drivers, older women's travel patterns are significantly different from older men's, and they self-regulate their driving behaviors more. Self-regulation means that they are less likely to drive at night, less likely to drive in congested traffic, less likely to drive when they don't feel well, less likely to make left turns, more likely to make all right turns around the block, and just driving less, which includes staying home.

Older women give up driving substantially earlier than comparable men and for "less drastic" reasons. Studies in lowa following older drivers found that the precipitating factor of older men giving up driving is the third stroke or heart-attack! Women, however, give up driving because of vague reasons such as they don't feel confident, they don't like it, etc. The reasons are not often a precipitating event, illness, stroke or heart attack. Usually by the time older women have a stroke or heart attack, they've already given up driving. The problem is that women have fewer resources to meet their mobility needs when they stop driving, although they're just as likely as men to be living in suburbs or rural areas.

\section{Implications}

If women continue to give up driving earlier, and not driving as much, there are going to be substantial mobility issues. If however, as has been happening over time, they come to more resemble the driving behaviors of older men (e.g. driving alone, driving more, more dependent on the car), then there are going to be safety issues.

What is noteworthy about the safety issues is that women have fewer crashes than men, by large margins, through all age categories. So, when it is said that older women are, or might become, less safe, they are not being compared to men. They would have to be much less safe to drive with the crash rates that older men have, but to current generations of older women. If older women in the future drive more, start to have more male-like driving behavior, we will see skyrocketing crash rates even though they will be no where near the crash rates of comparable men.
Sandra Rosenbloom, Ph.D., is professor of planning, natural renewable resources, gerontology and women studies at the University of Arizona. She was the director of the Drachman Institute for Land and Regional Development Studies, a research and public service unit of the university (1990-2004).

Geiska Baker is a graduate student of the MCRP program. 
There are obvious mobility implications in this as well. There is substantial evidence that women renounce driving often before they need to; that is they are still competent drivers, they just don't feel like competent drivers. There is a misconception in the data that with age, women are less likely to drive. In the future there will be really different people driving. New older driver cohorts are on the horizon. The current cohort of 85-and-over represents women who never learned to drive. In 2003, we found 84 percent of women coming into their senior year (age 65) were drivers.

So, the gap is definitely narrowing, and this cohort (65-69) is going to move across time, and in the cohort behind it, the gap is even smaller. The gap is largely a difference in the licensing rates of minorities; white men and white women have licensing rates almost the same. U.S. licensing rates are substantially lower among minority women. In fact, the gap between Hispanic men and Hispanic women is almost twice that as between Hispanic men and White non-Hispanic men.

\section{Drivers}

As the sample is disaggregated, it tells us that when older people are drivers, there is no statistically significant difference between men and women's mode preferences. Both genders take over 90 percent of trips in a car. However, if you're not driving, you still take two thirds of your trips in a car, for both men and women, and you're much more likely to walk if you use public transportation.

The National Household Travel Survey 2001, which is the latest available data, establishes that women are more likely than men to travel in a car if they are non-drivers. This survey doesn't ask people if they are licensed drivers, because there were a lot of people driving without licenses, particularly in the immigrant and ethnic groups. It does ask however, "do you drive?" Some say that there are many who have a license and may not be driving, but this data show that these are people who are driving whether they have a license or not.

All men over 65 drive more than women over 65 and, if they are drivers, they make more trips per day. If they are not drivers, women make more trips. So, the second difference is found between people who drive and people who don't drive.

Another problem is that we don't know why these women are not driving; they may have given up, may never have been drivers. The national dataset conflates two very important things; whether you never drove or whether you gave up driving, you're in the same category. As a consequence, the mathematical averages of non-drivers may actually represent no one's behavior. It could be argued that if you have never driven it may be that you have organized your life so you can exist without driving. In other words, you live near your relatives, you live in a denser neighborhood, you live near public transport, or you live in a place where you can walk.

Those that must give up driving, on the other hand, may actually be more disadvantaged, because they live in suburbs, in places that have no alternative to driving. They're not living near their family; they may not have any family. Seventeen percent of baby-boomer women in the United States never had a child, and, increasingly, women are coming into their senior years single, divorced, widowed or never having been married.

Remembering why men renounce driving, makes clear why it is men make fewer trips when they're non-drivers. They are so ill or have so many disabilities by the time they give up driving, that some of that is reflected in their trip record. The second reason discovered through focus groups discussions, 
is that men won't ask for directions, and they won't ask for rides; where women seem more willing to ask for rides when they can't drive.

Another significant difference is if you're a driver, and you're a woman, look how much you're not driving the car you're riding in. On the other hand if you're a man, even if you are over 85 years of age, you're driving almost two-thirds of the time. This is important because there is a real problem with driving experience. Contrary to the belief that older drivers have more crashes than younger drivers, they do not; and they'd have to go a long way to have more crashes than $18-25$-year-old boys.

Research in Finland on driving exposure found that what is happening among older drivers is that they actually have more accidents per exposure, but less per capita, until around 85 years of age. They discovered that what really predicts crashes is "low driving exposure." In other words, regardless of age, if you don't drive very much you're more likely to have crashes. The fact that women drivers are often riding as passengers means that they're not getting the experience they need to continue to be good drivers which exacerbates the vicious cycle of not feeling confidant, not driving, and relinquishing driving early.

Only in the youngest cohorts do women drive nearly as much as men. The data shows women $16-24$ drive 82 percent as many miles as their male counterparts and as age goes up they drive fewer and fewer. So, if we're waiting for the youngest women to make it to 65 before the trends equalize, we're going to be waiting a long time. Even though there are changes in mobility and drivers licensing, there is more dependence on the car among younger women, though there are still substantial differences.

\section{Focus Groups}

During focus group research in both America and Great Britain, it was found that many women don't drive because men are constantly criticizing them. They are criticizing even though the statistics show that women are inherently safer drivers than men. To the question "Why don't you drive as much as you used to?" these are some of the answers:

- Female driver in an US focus group: Sat beside her husband, never really drove, even though she had a driver's license, and now there is nobody else in the car, and she doesn't feel confident. She doesn't go out as much, she's afraid of being in the car.

- Female driver, Birmingham, England: The stress of the road.

This introduced an interesting characteristic of British women that wasn't true of a lot of American women. Many British women thought of driving as a chore and didn't see it as pleasurable, liberating, or doing anything they wanted to do. They believed that when they had reached a certain stage in their life, they shouldn't be driving -- for example, past the age of 60 or 65 . The contrary belief of one woman in a focus group was met with much criticism from the other women, even though she was the only one of them who had lost her husband and had no one to drive her.

\section{Parents of Older Drivers}

Self regulation was also introduced with parents of older drivers. What was interesting was how different the parents were in the UK and in the United States. In the UK, adult children of older parents very much wanted that their older parents stop driving. In the United States, the adult children of older drivers were concerned or worried, but they never had the same feeling that their parents ought to 
stop driving. This may be, in part, because Americans are more invested in the car so that the adult children did not want to put themselves in that position. They could see what would happen to them if they had to stop driving, so they were unwilling to say that their parents should. Furthermore, they could see what would happen to their lifestyle if they had to start driving their parents around.

- Female driver, Sheffield, England: "My husband criticizes me, he tells me what l'm doing wrong and it's just easier to let him drive."

Many of the adult children complained about their father's driving, and they felt that it was almost impossible to get through to them. If they said anything to their male parents, it started a fight or he would not want to hear about it. There have been some focus studies done in the United States where the researchers found people who actually disinherited their children for saying "dad, you shouldn't be driving." Both in the United States and the UK, people universally said that their mothers listened to them, initiated conversations about how they drive and when they were told they were a bad driver, were quite willing to cease or reduce driving, but it was almost impossible to say anything to the father.

It was difficult to get older people to make any comments at all. When asked "Do you think that you're a better driver because you have years of experience?" most would answer, yes. Then they would immediately launch into a discussion about how bad younger drivers were, and it was clear in both the United States and in Britain that this was not the first time the issue had been raised; they were very resistant.

They were asked "what will you do when you have to stop driving?" To this, they provided answers such as "I'm never going to stop driving" or "I don't know." It was really difficult to engage them, particularly the men. So much so in fact, that when during the screening, people were asked to identify themselves as a current driver, former driver or someone who never drove, so that they could put together the focus groups.

In every focus group at least one older gentleman would identify himself as a driver who didn't have a license anymore, didn't have a car and had no insurance. But he still identified himself as a driver! This is clearly much more a part of a man's persona than it is of woman's, and the kids can't get the parents to do what they want them to do. The mothers might listen - are more likely to listen -- but the fathers won't listen at all.

- Seventy one year old female non-driver, Tucson, Ariz. Tucson is a very automobile-oriented culture, so it was sort of a surprise at this woman who didn't drive. She had a driver's license before she retired to Tucson, used public transport, but she didn't drive. She then moved to Tucson to be with her brother, and she feels ready to get in a car and drive again. However, her brother insisted on driving. He is 81 and not her husband but he still believed that it was his job to drive.

By examining trends, similarities begin to appear. Men and women are much more alike if that gap is closing, though it's not going to disappear, because among younger women, minority and ethnic women are less likely to drive. There will still be a substantial number of women coming into their senior years who have never driven. But at the same time, certainly in the majority culture, that gap is closing.

Female "automobility" is increasing. In other words, there are more women who drive, have driven themselves all their lives, are likely to own and use a car, and more percentage of their trips than ever 
before are taken by car. Along with this growing "automobility" and access to the car, is the double and triple digit increase in trips made and miles traveled in a car. There is also a correlation in the increased "automobility" and a decrease in the use of other transport.

\section{Transit System Challenges}

In 1995, a national study showed that older people are more likely to use public transport than younger people. Many researchers assumed that the report indicated that older people suddenly decided to use public transport and walk for more of their trips. What was actually represented, however, was a generational difference. It was women, who had never driven before, suddenly being replaced by women who were drivers. Furthermore, the transit system is geared to serve origins and destinations at conventional work times, and not the origins and destinations that older people generally want to travel to. Of course some of them are the same, like malls, but most older people are not going to the large employment centers or other places that public transport is going.

The transit system isn't as well structured to make non-work trips as it is to make work trips, regardless of the traveler's age. So, when older people leave the workforce, they're often exchanging work trips for non-work trips; work trips made by public transport for non-work trips that you can't make by public transport in most places. The perception of personal security is an issue as well. If you think you are unsafe you won't use transit. There is so much to be improved in public transit to accommodate older people; it is just far too expensive in most cases.

In 2000,75 percent of the U.S. population over 65 lived either in rural or suburban areas. There is no suburban definition in the census. The suburban distinction is derived in the census by taking central cities out of metropolitan areas and what's left, outside of rural, is suburbs. The problem is that the central city is equal to the jurisdictional boundaries of a community. So, you can be 42 miles from downtown Tucson and be considered "central city Tucson" in the way the census definition works. This means that the figure of 75 percent is probably too low. It underestimates the number of people living in low density. It underestimates the number of people that live in areas where there is poor access to public transport or other alternatives. So, now there are people increasingly dependent on the car, older people increasingly living in places where there is no alternative.

This is a serious issue and why it's so important to find ways for older-people to: a) continue driving, particularly women and others disadvantaged by these trends, and b) talk about housing and landuse options that will allow people to have greater access, particularly older women because they are substantially less likely to be married and more likely to be living alone than older men.

The Finnish researchers mentioned earlier suggest that one way to keep women driving is to encourage them to drive before they turn 65 . This does not mean they have to drive more, just encourage them to drive when they're in the car. Encourage them to say to their husbands and partners, "Hey, I need to drive half of the time, and you need not say anything to me when I'm driving unless I'm about to get us killed! You need not depreciate me, criticize me. You need to let me drive that car for our health in the future!"

A woman in New Zealand said "why should I care about silly women who can't discuss this with their husbands?" It is the overwhelming percentage of women, so silly or not, women need to be encouraged to instigate these conversations. The need is to encourage them to drive more, period. 
But the most important thing is for husbands and wives, partners, to sit down and have this discussion before it is too late.

\section{Future Research Needs}

There are profound differences in crash outcomes due to innate physical differences between men and women. It's very important to look at those differences in terms of having crashes in the first place and in terms of crash survivability. This is a women's issue.

Another area for future research is the impacts of the array of new modifications available in new cars on older-people. There are issues here in terms of the driving tasks there as well as issues of crash survivability and outcome. Research is needed and it should also be done by gender.

Driver training programs deserve some attention in terms of developing and testing some prototype programs. Encourage the private sector to adopt that kind of curriculum, and make sure that whatever that curriculum is, that it is a strong proven relationship between what you're teaching people in a car or in a classroom, and crash outcomes.

\section{Land Use, Community Design and Housing Options}

This is part of a whole bigger issue of land use, community design, planning and housing options. For the most part, people are aging in place. In other words, they are living their senior years where they lived at 45 and still in the workforce. While there are exceptions, particularly noted in places such as Arizona or Florida, in fact what's happening is the percentage of people who move on retirement has been dropping every decade for the last 40 years. There are more people over 65 , so a smaller percentage of the larger number is still absolutely more people and they are going to a select few places, such as Florida. When they're moving, they move to the suburbs.

Some places, such as North Carolina, have made it part of the economic development policy to recruit people at 60 or 65 to move into their rural areas. In Vancouver, they built senior-friendly development, restricting sales to those who stay within the neighborhood, because that is what people are attached to, even more so than their homes.

It is necessary to find housing options for older women living alone, because even when gaps are closed, women are still living longer than men. So, there is a need to look at the kinds of things that will facilitate where they want to be, and keeping them out of institutions. It is a complicated picture and is more difficult for women than men. The Vancouver model needs to be expanded.

\section{Linking Research to Policy}

If you're talking about transportation planning, you have to know why different people respond, you have to do that market segmentation, which is considered perfectly acceptable in the private sector, and it should be in the public sector and public-private partnerships as well. Segmentation research is going to change the kind of policy responses and transport that policy makers choose. It's going to make a difference, and that this type of information is needed to design mire useful multi model transit policy. 